\title{
Demandas multi e interculturales y antropología
}

\author{
Yolanda Jiménez Naranjo
}

GUNTHER DIETZ, 2003

\section{Multiculturalismo, interculturalidad} y educación: una aproximación

\section{antropológica}

Universidad de Granada-CIESAS, Granada.

G unther Dietz, en su libro Multiculturalismo, interculturalidad y educación: una aproximación antropológica, realiza una serie de reflexiones y propuestas en torno al proceso de institucionalización y academización del discurso multiculturalista y su posterior desarrollo en procesos interculturales, vinculados principalmente con la esfera educativa e íntimamente relacionados con el quehacer antropológico. Dada la conexión que se realiza entre multiculturalismo y/o interculturalidad, su proyección en lo pedagógico y la creciente importancia de la antropología en estas esferas, considera la necesidad de adentrarse en una reflexión metaetnográfica sobre el quehacer antropológico, una propuesta conceptual sobre los términos de cultura e identidad y una propuesta metodológica que conecte la reflexión meta-etnográfica y conceptual.

YOLANDA JIMÉNEZ NARANJO: Universidad de Granada.

Desacatos, núm. 14, primavera-verano 2004, pp. 264-267.

Proceso de institucionalización y academización de lo multi e intercultural

En los Estados Unidos de la década de 1960 confluyen diversos movimientos sociales donde participan, entre otros, colectivos feministas, ecologistas, afroamericanos e indígenas. Estos movi-

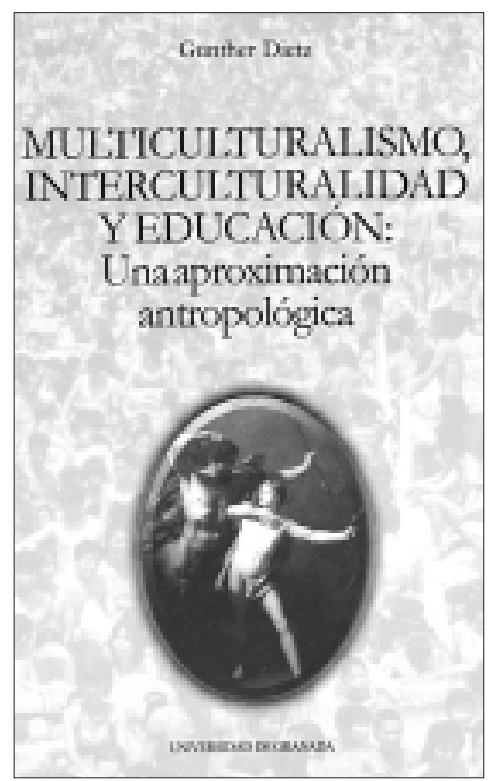


mientos comparten el cuestionamiento de la realidad como construcción legitimada que cimenta la conformación desigual de la sociedad. Ellos darán comienzo a los movimientos multiculturalistas. Posteriormente, entrarán en un proceso de institucionalización y academización que va a permitir entablar un debate en torno a la interculturalidad una vez que estas problemáticas permeen las ciencias sociales.

En el proceso de academización del movimiento multiculturalista, el autor nos menciona la aproximación que se realiza hacia el posestructuralismo y el posmodernismo: se acerca al posestructuralismo en tanto que comparte la idea y la intención de deslegitimar la construcción hegemónica que enciera las claves del relato que justifica la desigualdad social existente. De igual forma, se aproxima al posmodernismo en tanto que rechaza las polarizaciones simplistas y esencialistas de las identidades y comparte con él un enfoque constructivista, pluralista y hasta relativista en la formación de las identidades. De forma transversal a estas problemáticas, se incluye un debate sobre el futuro de las sociedades occidentales, donde se contraponen a menudo la visión universalista de Occidente frente a los particularismos contrahegemónicos (fuera y dentro de lo que se considera Occidente).

Entre las influencias posestructuralista y posmodernista el multiculturalismo se bifurca en dos corrientes, que Gunther Dietz menciona como "la condición posmoderna" y "el discurso poscolonial”, conjugado éste último con la "teoría crítica" del multiculturalismo. En la primera de ellas lo posmoderno, la concepción constructivista y plural de las identidades, la crítica al universalismo, a la normatividad y a la imposibilidad de las definiciones cerradas gana espacio frente a una postura (la poscolonial o teoría crítica) donde las desiguales estructuras sociales siguen siendo vigentes para explicar y conocer procesos multiculturales. En esta corriente se emprende igualmente una fuerte crítica tanto al proceso de esencialización cultural y étnica como a la compatibilidad que en ocasiones se ha producido entre la mercantilización de la cultura y las prácticas xenófobas dentro de lo multicultural.

En el proceso de institucionalización y academización la escuela aparece como el espacio privilegiado para este tipo de prácticas, sobre todo si entendemos la preferencia cada vez más nítida por las ideologías reformistas en lugar de las transformacionistas. Se produce por tanto una "pedagogización del discurso multiculturalista" que desembocará en una "pedagogía intercultural”, donde lo pedagógico y lo antropológico se vinculan (el autor

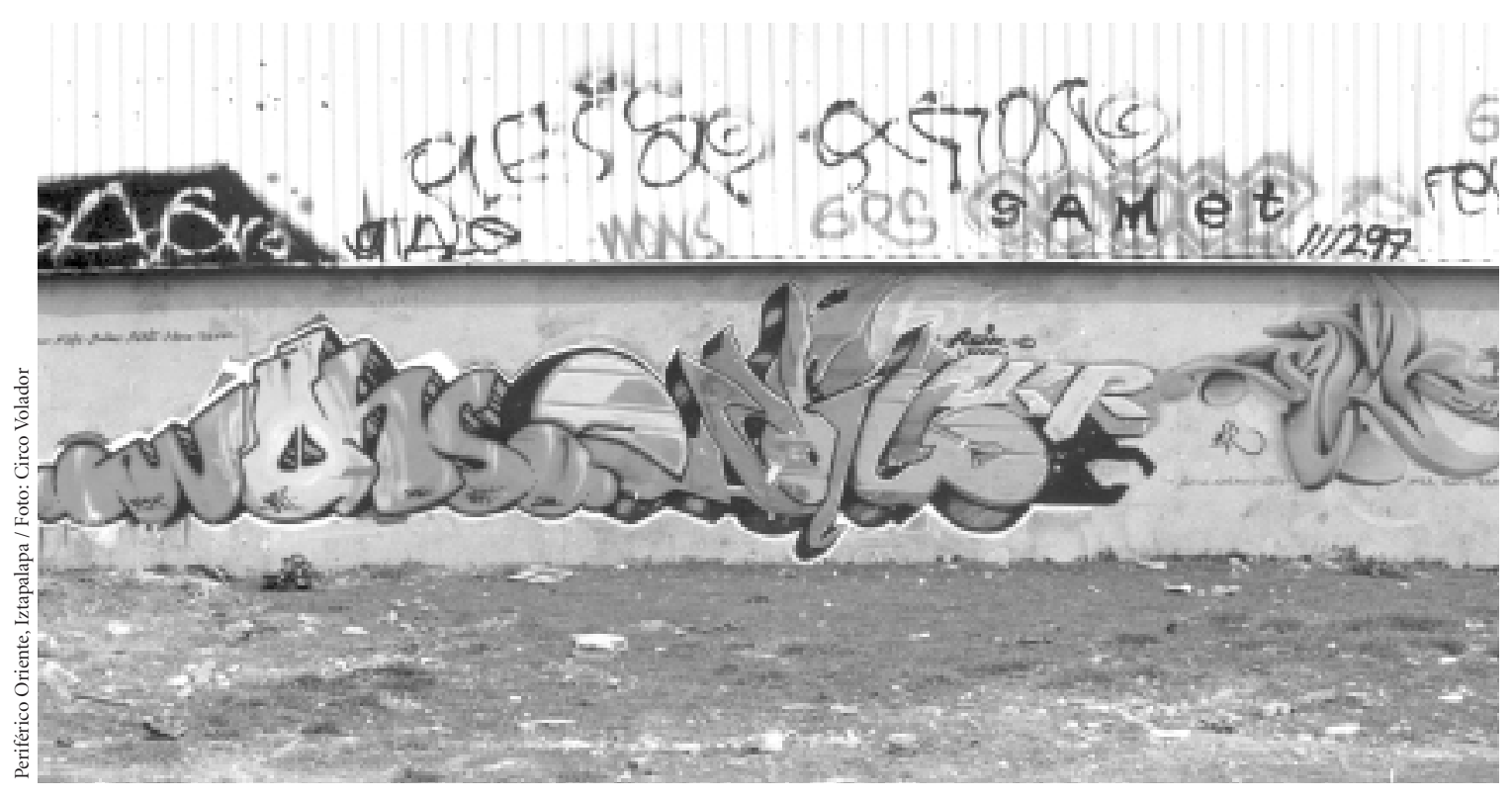




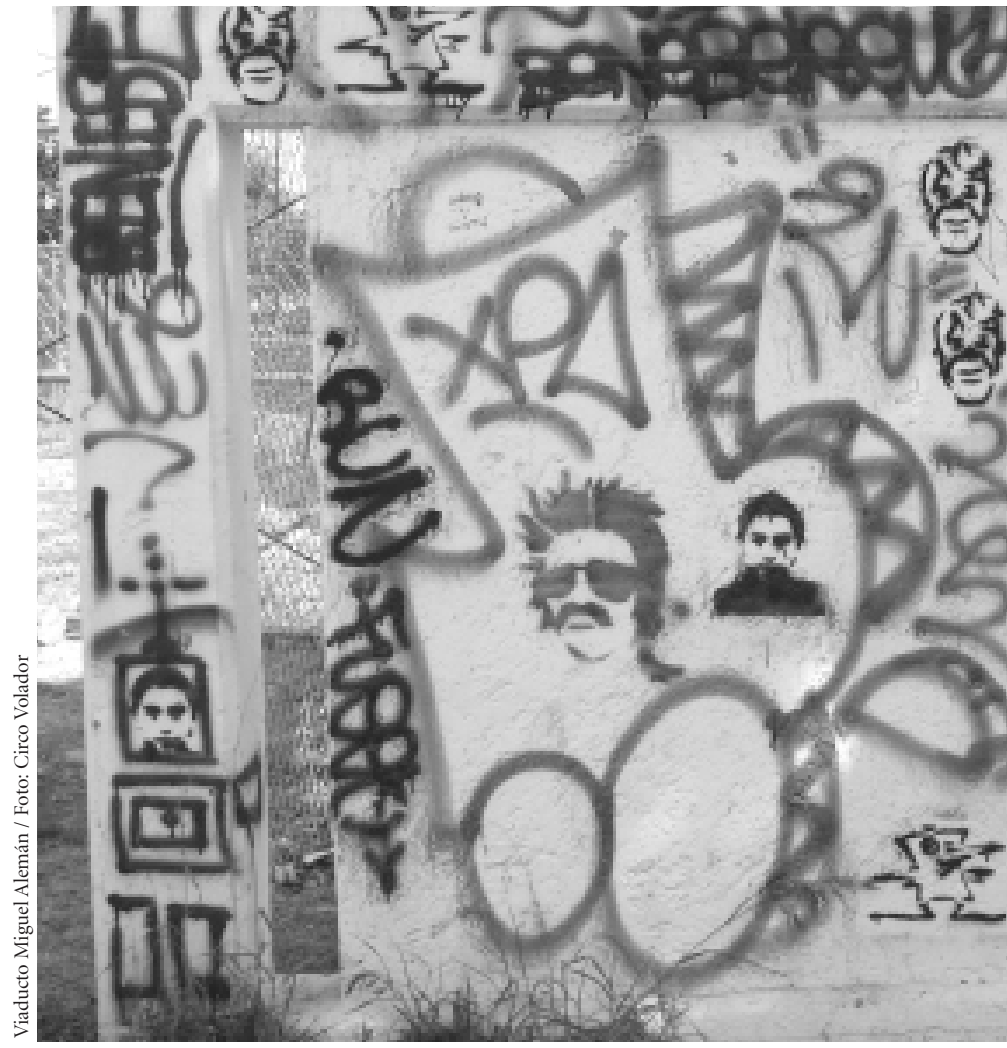

le llama "encontronazo", dadas las condiciones en las que la pedagogía hace uso de lo antropológico). Pero la misma antropología está en estos momentos en un proceso de cambio y redefinición, donde su intervención en los procesos llamados ahora multi e interculturales vinculados con las grandes transformaciones sociales vividas en las dos ultimas centurias la obligan a una justa y merecida reflexión. Para ello Gunther Dietz realiza un análisis meta-etnográfico, una propuesta conceptual sobre los términos de cultura e identidad y una propuesta metodológica que conecta las anteriores reflexiones. Todos ellos hacen más comprensible su vinculación con las nuevas propuestas interculturales.

\section{Planteamiento meta-etnográfico}

A raíz del proceso de independencia en los países poscoloniales y del surgimiento de los movimientos étnicos se produce una crisis de "representación" y de "identidad disciplinaria" en la antropología, hasta entonces ubicada en el clásico método malinowskiano.

Como respuesta a tal situación, desde la década de 1970 y los comienzos de la de 1980 las estrategias etnográficas se polarizan entre el relato autoreferencial de la experiencia etnográfica y la del ser útil a los objetos-sujetos de estudio. En el primer caso, la "etnografía experimental" o posmoderna se aleja de las reivindicaciones políticas encerradas en los contextos en los que se inserta y pretende no tanto descolonizar el trabajo de campo ni las relaciones asimétricas en él existentes, como el relato etnográfico (que va de los "etnógrafos-autores" a los "etnógrafos-lectores"), con lo que se evaden las responsabilidades políticas de su trabajo, donde lo dialógico del relato no soluciona las asimétricas relaciones de campo.

Por ello, la otra vertiente, opuesta a la mencionada, insiste en descolonizar no sólo la representación, como pretendían estas teorías, sino también los usos de lo que aún es nombrado "dominación imperialista" por parte de la antropología. Se pone el énfasis en el activismo como rasgo principal de una antropología que en sus pretensiones descolonizadoras se convierte en una antropología de la liberación.

Sin embargo, Gunther Dietz argumenta que en esta última opción, sobre todo en las medidas adoptadas por las políticas anglosajonas, con frecuencia se recurre al empoderamiento como vía para descolonizar la antropología, pero no queda analizado de igual modo el carácter (neo)colonial de estos nuevos actores. Por ello, el autor propone que antes de identificar al colectivo destinatario de medidas de empoderamiento sería preciso analizar la desigual distribución del poder también al interior del grupo, entre éste y la sociedad así como entre el grupo destinatario de la investigación y quien la realiza.

De ahí que Dietz proponga una estrategia metodológica híbrida que refleje la complejidad de las relaciones asimétricas en los niveles antes mencionados, donde se conciba a la etno- 
grafía "como procedimiento "localizado' de comunicación intercultural", que nutriéndose de una hermenéutica intercultural posibilite una etnografía doblemente reflexiva, donde esa reflexivilidad no debe detenerse sólo en el aspecto clásico de la hermeneútica, más centrado en el aspecto semántico y conceptual, sino fundamentalmente como un giro a la praxis cultural para realizar una hermeneútica pragmática, donde también los contextos en los que son generados los sentidos compartidos nos permiten acercarnos a esa traducción mediante una reflexividad dialógica.

\section{Propuesta conceptual: cultura-identidad}

El autor considera la importancia del análisis de conceptos como cultura, etnia y etnicidad, ya que aún se siguen usando y operacionando bajo esquemas de la antropología del siglo XIX, por lo que con frecuencia se produce una esencialización de la diversidad cultural, a pesar de que considera que los usos de tal término en la antropología del siglo XX se alejan de un enfoque esencialista.

Por esta razón ofrece un enfoque no esencializado de la cultura, concebida de una forma dinámica, holística, heterogénea y habitualizada o rutinizada a través de la praxis, que nos permite concebir tanto lo objetivable como lo subjetivo en el concepto cultural.

De la misma forma considera la importancia de partir de un concepto no esencializado sobre la etnicidad, producto de un proceso en continua cons- trucción, donde, en relaciones de interculturalidad, se producen procesos de adscripción y autoadscripción étni$\mathrm{ca}$, en virtud de ciertas características que los actores eligen como propias o ajenas. Sin sostener que la elección de esas características culturales sea ficticia o falsa, pues se realiza con base en unas prácticas culturales concretas. De tal modo, la cultura tiene un enfoque centrado en la praxis rutinizada y la etnicidad se conceptualiza como identidad construida (dentro de las relaciones de fuerza existentes dentro de la sociedad). Tal distinción nos permite no igualar ambos conceptos y distinguir entre los procesos de reproducción cultural y los procesos de identificación étnica, lo cual nos permite no confundir ni igualar los niveles objetivos y subjetivos, los intraculturales y los interculturales, la praxis y el discurso.

\section{Propuesta metodológica: de lo emic y lo etic}

En relación con la reflexión que hemos denominado meta-etnográfica y a la aclaración sobre la relación que guardan los conceptos de identidad y cultura, el autor propone un enfoque etnográfico que permanentemente oscile entre una perspectiva emic y otra perspectiva etic. Su combinación (pero no fusión) es la que permite distinguir la praxis del discurso, lo cultural de lo étnico, el mundo, según el "experto" académico, de su propio mundo de vida, y con ello la posibilidad de una etnografía doblemente reflexiva donde los constructos emic y etic en continuos encuentros puedan hacer de la labor antropológica un proceso que, sin renunciar a su complejidad (más bien tomando conciencia y participando en ella), participe de un proceso dialógico y reflexivo entre todos los actores que participan en el proceso de investigación.

Por ello finalmente presenta un modelo etnográfico tridimensional que conjuga una perspectiva centrada en el actor a través de una perspectiva emic donde se establecen las estrategias de identidad, una perspectiva centrada en la praxis, en el habitus intracultural e intercultural a través de una perspectiva etic y un análisis centrado en las instituciones donde se articulan tanto los discursos de identidad como las prácticas habitualizadas.

Para finalizar, faltaría comentar que en momentos como los actuales, donde lo multicultural y lo intercultural se sitúan en diferentes campos disciplinarios y aparecen con fuerza emergente dentro de las políticas de los Estados, es importante que la antropología, disciplina privilegiada en el campo de lo cultural, revise y analice tanto su posicionamiento conceptual como epistemológico. Los usos que del componente cultural se realizan por actores tan diferentes, y posiciones igualmente diversas, deben llevar a una reflexión sobre el mismo quehacer antropológico y una propuesta que pueda hacer de la antropología una disciplina crítica hacia la reflexión cultural en momentos de importancia creciente de las prácticas multi e interculturales. El libro de Dietz es una excelente orientación en este sentido. 